\title{
AstraZeneca taps the Cambridge wellspring
}

\section{By Michael J. Haas, Associate Editor}

AstraZeneca plc has unveiled plans for the R\&D center and global headquarters it will build in Cambridge, U.K. - the next major step in the pharma's strategy to improve pipeline productivity that it hopes will help it recover growth and regain ground in scientific leadership. The company expects that the new center will drive therapeutic innovation by allowing it to tap world-class research through partnerships with nearby institutes.

Last year, AstraZeneca announced plans to build the Cambridge headquarters - which would make it the first global pharma to establish a major research facility in the city. The new site is part of the pharma's larger goal to concentrate its small molecule and biologics R\&D in three places by 2016-with the Cambridge headquarters joining two existing sites in Gaithersburg, Md., and Mölndal, Sweden.

The move is one facet of a restructuring that AstraZeneca began to implement in 2012 that included discontinuing R\&D at neuroscience sites in Sodertalje, Sweden, and Montreal, Quebec, Canada, and the elimination of about 2,200 R\&D positions.

Menelas Pangalos told SciBX, "The way to do great science in pharma is changing. Excellent internal science needs to be married to outstanding external science and access to world-class scientists. Thus, to develop innovative medicines that are differentiated from the competition, we must be able to attract and retain great scientists internally and also work collaboratively with the very best external scientists"-both of which the Cambridge center will enable AstraZeneca to do.

"Some projects will align with AstraZeneca's research strategy but others will not, and the pharma has shown openness and flexibility in agreeing that MRC can determine which projects use the company's compound library and screening capabilities."

-Chris Watkins,

Medical Research Council

life science ecosystem that includes 300 biotech and medical technology companies and its proximity to leading academic and research institutions such as the University of Cambridge, the MRC Laboratory of Molecular Biology, the Wellcome Trust-MRC Institute of Metabolic Sciences, the Cancer Research UK Cambridge Institute, Addenbrooke's Hospital, the Wellcome Trust Sanger Institute and the Babraham Institute.

He also noted that Cambridge is one corner of a "golden triangle with London and Oxford that has a breadth, depth and quality of scientific innovation comparable to Boston and San Francisco."

Although AstraZeneca was successful in attracting top-tier scientists (o attract world-class scientists to a magnet for talent.

\section{Taking the lead}

Pangalos said that the new R\&D center builds on existing collaborations the pharma already has in Cambridge, and "as our presence in Cambridge grows over the next few years-and we establish ourselves as a great scientific partner-I believe we will see further opportunities for institutions.

In 2011, AstraZeneca and the Medical Research Council (MRC) partnered to repurpose 22 of the pharma's deprioritized and discontinued compounds-a program that expanded in July to include 6 more pharmas. ${ }^{1}$

In February, AstraZeneca partnered with the Cancer Research UK Cambridge Institute to move up to 60 of the pharma's scientists into the institute over the next 3 years.

In May, AstraZeneca and the MRC Laboratory of Molecular Biology partnered to fund a range of preclinical research projects on disease biology. AstraZeneca will contribute up to about $£ 6$ million ( $\$ 10$ million) and the MRC up to about $£ 3$ million ( $\$ 5$ million) over 5 years. Projects funded by the partnership will support the existing R\&D activities of the two organizations but will not focus directly on drug development.

Also this year, AstraZeneca partnered with the MRC to create the AstraZeneca

Pangalos is EVP of innovative medicines and early development at AstraZeneca.

The new $R \& D$ center in Cambridge will have all of the capabilities needed to support discovery and development of small molecules, proteins and biologics in cancer as well the pharma's programs in cardiovascular disease, diabetes, asthma, chronic obstructive pulmonary disease (COPD) and neuroscience, he said.

Pangalos said that AstraZeneca chose Cambridge as its new hub because of the city's history of scientific excellence, a thriving
MRC UK Centre for Lead Discovery-which the new R\&D center in Cambridge will house-to identify new targets and therapies to treat a range of diseases.

The MRC is always looking to work in innovative ways with industry and has a long-standing and productive relationship with AstraZeneca, said Chris Watkins, director of translational research and industry at the MRC. The Lead Discovery center "addresses a key strategic priority for the MRC in enabling the discovery of new pathways involved in human disease through the use of novel small molecules and brings 


\section{ANALYSIS}

\section{TRANSLATIONAL NOTES}

together the respective and complementary strengths of academia and industry," he said.

Under the terms of the partnership, the MRC gains access to AstraZeneca's library of 2 million compounds and state-of-the-art high throughput screening technology-

"To develop innovative medicines that are differentiated from the competition, we must be able to attract and retain great scientists internally and also work collaboratively with the very best external scientists."

- Menelas Pangalos, AstraZeneca plc

economic growth."

He added, "Some projects will align with AstraZeneca's research strategy but others will not, and the pharma has shown openness and flexibility in agreeing that MRC can determine which projects use the company's compound library and screening capabilities."

However, Watkins said, AstraZeneca will have the first option to negotiate agreements on Lead Discovery projects that do align with its research interests.

Pangalos said that AstraZeneca and its partner institutions in Cambridge will jointly define the metrics for success and project milestones for each collaboration and will regularly review progress toward the pharma's goal of achieving "our most critical deliverablegetting new medicine to patients.”
According to Richard Burton, head of communications for innovative medicines and early development at AstraZeneca, the R\&D center will cost the pharma about $£ 330$ million ( $\$ 552$ million) to build and will receive no public funding. The center will house over 2,000 employees, including the majority of the 1,600 small molecule researchers who will relocate from the pharma's Alderley Park facility and all of the biologics researchers from its MedImmune LLC unit at the Granta Park facility outside Cambridge.

However, AstraZeneca is not waiting for the center to open before expanding its presence in Cambridge: 70 AstraZeneca scientists have already relocated to 3 interim facilities in the Cambridge area, including the current MedImmune site at Granta Park, and another 400 will move into the city by year end, Pangalos said.

The 2012 restructuring initiative cut 7,300 positions and was expected to result in about $\$ 1.6$ billion in annual savings by the end of 2014. Including the 2012 cuts, AstraZeneca has eliminated nearly 29,000 positions since beginning restructuring efforts in 2007.

Haas, M.J. SciBX 7(32); doi:10.1038/scibx.2014.942

Published online Aug. 21, 2014

\section{REFERENCES}

1. Boettner, B. et al. SciBX 7(29); doi:10.1038/scibx.2014.849

COMPANIES AND INSTITUTIONS MENTIONED

Addenbrooke's Hospital, Cambridge, U.K.

AstraZeneca plc (LSE:AZN; NYSE:AZN), London, U.K.

Babraham Institute, Cambridge, U.K.

Cancer Research UK Cambridge Institute, Cambridge, U.K.

Medical Research Council, London, U.K.

Medlmmune LLC, Gaithersburg, Md.

MRC Laboratory of Molecular Biology, Cambridge, U.K. University of Cambridge, Cambridge, U.K.

Wellcome Trust-MRC Institute of Metabolic Sciences, Cambridge, U.K.

Wellcome Trust Sanger Institute, Cambridge, U.K. 